\title{
STUDIES ON DIABETES MELLITUS: THE RELATION OF STRESS- FUL LIFE SITUATIONS TO THE CONCENTRATION OF KETONE BODIES IN THE BLOOD OF DIABETIC AND NON-DIABETIC HUMANS ${ }^{1}$
}

\author{
By LAWRENCE E. HINKLE, JR., GEORGE B. CONGER, AND STEWART WOLF \\ WITH TECHNICAL ASSISTANCE OF BETTY L. PUGH aNd CLIFFORD J. EDWARDS
}

(From the New York Hospital and the Department of Medicine of Cornell University Medical College, Nere York, N.Y.)

(Submitted for publication November 12, 1949; accepted, March 6, 1950)

Investigators have long been aware of the fact that pronounced metabolic fluctuations occur in diabetic humans in the absence of infection, trauma, or intercurrent disease, and despite faithful adherence to a previously adequate regimen. The possibility of "neurogenic" factors as a cause of such fluctuations was first considered after Claude Bernard's production of diabetes in experimental animals by puncture of the floor of the fourth ventricle. Later the diabetogenic effect of the anterior pituitary was discovered by Houssay, and more recently investigators have recognized the importance of the adrenal as well as pituitary hormones in diabetes. In fact, Conn and his collaborators have actually induced a state of temporary diabetes in healthy persons by the administration of pituitary adrenocorticotrophic hormone (1). This work has been paralleled by that of Selye (2), who elaborated the concept that the pituitary and adrenal were part of a general mechanism through which vertebrates adapt to threats to their integrity. Exposure to cold, exhausting exercise, and surgical operations have been considered among such threats or stresses which lead to the discharge of anterior pituitary and adrenal cortical hormones. Perhaps the commonest stresses that the human being encounters, however, are those concerned with problems of interpersonal relationship-words or events perceived by the individual and either consciously or unconsciously evaluated by him as threatening because of his past experience or conditioning.

The likelihood that personal conflicts arising out of stressful life situations were germane to the course of diabetes mellitus has been pointed out by a number of investigators during the last 15

\footnotetext{
1 Supported in part by grants from the Commonwealth Fund and the Estate of Lester N. Hofheimer.
}

years (3-11), but ketosis and coma have usually been attributed, as in the study of Rosen and Lidz (12), to willful abandonment of the prescribed regimen. The present communication concerns an experimental investigation of the effects of life situations upon some aspects of the glucose and ketone metabolism of normal and diabetic persons. Similar studies on blood glucose and on fluid balance will be reported separately $(13,14)$.

\section{PROCEDURE}

The subjects were patients from the Medical Clinics of the New York Hospital and volunteers from the hospital staff. The diabetic patients were average individuals encountered in a diabetic clinic, except that a relatively large proportion of the group were severe and labile diabetics. On each subject a detailed medical history was recorded as well as a physical examination and appropriate laboratory procedures. In addition, a detailed evaluation of his personality structure, life history, cultural background, present life situation, and significant conscious and unconscious conflicts, was undertaken through a series of interviews. Data were derived from discussion, questioning, associative procedures, dream analysis, social service case study, and psychologic tests. Moreover, the attitudes and motivations of the subject were assessed by observation of his behavior and reactions, especially during the discussion of difficult life experiences, by things said and left unsaid, by statements from other members of his family, and so forth. The investigation of most subjects included from ten to 25 one-hour sessions over a period of from three months to a year. Special note was made of the content of the situations when ketosis or hypoglycemia occurred, their significance to the subject, and his reaction. This inquiry revealed a striking coincidence between the occurrence of stressful life situations and clinical decompensation of the diabetes, the details of which are reported elsewhere $(15,16)$.

The experiments were performed in the morning after an overnight fast. All subjects had been receiving diets of at least 1,400 calories containing at least $100 \mathrm{gms}$. of carbohydrates for several weeks prior to the studies. 
No strenuous physical exercise had been undertaken during the preceding 12 hours.

The diabetic subjects who had been receiving insulin had previously been regulated on a single morning dose of mixed protamine and regular insulin. This was omitted on the morning of the procedure. Breakfast was omitted also, but the subject was allowed to drink as much as two glasses of water upon arising. He came to the laboratory expecting the familiar "blood sugar test."

Upon the subject's arrival at the laboratory he voided and a sample of his venous blood was drawn. He was allowed to sit quietly for about an hour, diverting himself with popular magazines, and then second blood and urine samples were obtained. During the next hour he was interviewed while he lay on an examining table. The discussion concerned events, attitudes, and emotions which had previously been associated with episodes of ketosis or hypoglycemia. Every ten minutes throughout the interview blood was drawn from an indwelling venous needle through which a very slow drip $(60 \mathrm{cc} . / \mathrm{hr}$.) of $0.9 \%$ saline, containing $2 \mathrm{cc}$. of heparin per liter, flowed between sampling. At the end of the interview a urine sample was obtained, and the patient was strongly reassured and diverted. After a third hour of presumably neutral activity and diversion, final blood and urine samples were obtained. Smoking was not permitted at any time during the three hours.

During control procedures, as shown in the protocols below, it was found that the change from the sitting to the lying posture, the very small amount of intravenous fluid, and the small amount of heparin, had no effect upon the blood glucose and ketone bodies. A few of the subjects received sodium amytal, 0.2 to $0.3 \mathrm{gm}$. i.v., during the interview. It may be seen from the protocols that in this amount in these patients the drug had no specific effect upon the measured blood constituents. Elsewhere it has been shown in studies of various organs that bodily changes following the intravenous administration of sodium amytal depend upon the state induced in the patient, rather than upon a direct pharmacologic effect of the drug on the end organ (17).

Blood ketone levels were determined on duplicate samples by the method of Greenberg and Lester $(18,19)$ which in our experience is sensitive within less than 0.3 mg.\% at levels below $3.0 \mathrm{mg} . \%$. A modification introduced in later experiments in an attempt further to minimize the error was the use of a tenfold larger $(2 \mathrm{cc}$.) sample of blood. Blood glucose was determined by a method of Benedict (20-22) which responds closely to the "true glucose" content of the blood. Protein-free filtrates were prepared in early experiments by the Haden modification of the Folin-Wu procedure (23), and later by the method of Herbert and Bourne (24), which more accurately excludes reducing substances other than glucose. Under the conditions of our studies "normal" values for fasting individuals by this method are 55$80 \mathrm{mg} . \%$.

The reaction of each subject during the procedure was evaluated by observation of his behavior, including both overt manifestations such as tears, tone of voice, tachy- cardia, and sweating, and more subtle cues such as slips of the tongue, figures of speech, and fleeting gestures, which gained significance to the observer from his past familiarity with the subject. The statements of the subject during the interview were recorded, and at later interviews the data were supplemented by his conscious recollections and his free associations concerning all three of the experimental hours. This precaution was necessary since it could not be assumed that because he was apparently quietly and contentedly reading a magazine during the control hours, he was therefore relaxed and in an emotionally neutral state.

Whether or not an interview was stressful to the subject depended not merely upon the topics discussed, but upon the total meaning of the experience to the individual, and both his conscious and unconscious reaction to it. The evaluation of the meaning of this experience rested not only upon observations made at the time, but also upon a knowledge of the significance of such situations and topics to the subject, and the careful review of the situation with him at later interviews.

Upon both non-diabetic and diabetic subjects control procedures were carried out which were identical to those described above except that no stressful topics were discussed. It was actually more difficult to maintain neutral conditions over such a long period of time than it was to introduce a significant stress. A "blood sugar test" alone may have threatening implications for some diabetics. Furthermore, subjects without breakfast who spend three hours in a laboratory readily became bored and hungry, and often ruminate about their illness and c ther problems, thereby introducing a stressful stimulus into a control experiment. Therefore, in order to determine whether or not a subject had been in a truly neutral and comfortable state throughout a control procedure it was necessary to ascertain whether or not a stressful stimulus had been introduced inadvertently by the experimenter or the circumstances of the experiment, and whether or not the subject, through his ruminations, had been reacting to a remembered or imagined stress situation at a time when he appeared "calm and relaxed." Accordingly, subjects for control procedures were studied as carefully before, during, and after the procedure as the subjects who were exposed to stressful interviews, and their experiences were as carefully evaluated.

\section{NON-DIABETIC SUBJECTS : RESULTS}

\section{Control studies}

In 61 separate determinations in 15 healthy, non-diabetic individuals, at times when it could be ascertained that they were under relatively little stress, it was found that the peripheral venous blood ketone levels (total ketone bodies expressed as acetone recovered) lay between $1.4 \mathrm{mg} . \%$ and less than $0.2 \mathrm{mg} . \%$ - the latter being the lower limit which the method will detect. Most values 
TABLE I

Non-diabetic subjects: control studies*

\begin{tabular}{|c|c|c|c|c|c|c|c|c|}
\hline \multirow{2}{*}{ Subject } & \multirow{2}{*}{ Sex, age } & \multirow{2}{*}{ Situation } & \multicolumn{3}{|c|}{ Blood ketones, $m g . \%$} & \multicolumn{3}{|c|}{ Blood glucose, $m g . \%$} \\
\hline & & & 1st hr. & 2nd hr. & $3 \mathrm{rd} \mathrm{hr}$. & 1 st hr. & 2nd hr. & 3rd hr. \\
\hline $\begin{array}{l}\text { A } \\
\text { B } \\
\text { C } \\
\text { D } \\
\text { E } \\
\text { C } \\
\text { B } \\
\text { E } \\
\text { C }\end{array}$ & $\begin{array}{l}\text { F. } 22 \\
\text { F. } 30 \\
\text { M. } 31 \\
\text { F. } 23 \\
\text { M. } 35 \\
\text { M. } 31 \\
\text { F. } 30 \\
\text { M. } 35 \\
\text { M. } 31\end{array}$ & $\begin{array}{l}\text { Clerical work, relaxed } \\
\text { Clerical work, relaxed } \\
\text { Laboratory work, relaxed } \\
\text { Laboratory work, relaxed } \\
\text { Clerical work, relaxed } \\
\text { Neutral interview } \\
\text { Clerical work, relaxed } \\
\text { Clerical work, relaxed } \\
\text { Reading, talking, relaxed }\end{array}$ & $\begin{array}{l}0.7 \\
1.0 \\
0.7 \\
0.8 \\
1.0 \\
0.8 \\
0.6 \\
0.1 \\
0.6\end{array}$ & $\begin{array}{l}0.7 \\
0.9 \\
0.7 \\
1.0 \\
1.1 \\
1.0 \\
0.7 \\
0.4 \\
0.8\end{array}$ & $\begin{array}{l}0.5 \\
1.1 \\
0.6 \\
0.7 \\
1.1 \\
1.1 \\
1.0 \\
0.1 \\
0.8\end{array}$ & $\begin{array}{l}60 \\
59 \\
\\
64 \\
\\
70 \\
67 \\
43 \\
70\end{array}$ & $\begin{array}{l}60 \\
50 \\
60 \\
64 \\
64 \\
42 \\
67\end{array}$ & $\begin{array}{l}60 \\
64 \\
63 \\
58 \\
62 \\
43 \\
66\end{array}$ \\
\hline
\end{tabular}

* In all tables, ketone values recorded for the first and third hours are those obtained from the initial and final samples, respectively, and second hour values represent the highest value obtained during the second hour.

lay between 1.0 and $0.5 \mathrm{mg} . \%$. These levels are in accord with those reported by other workers, including Greenberg and Lester (18), and also by Weichselbaum and Somogyi (25), Crandall (26), Hubbard (27), and Marriott (28), who used various methods of analysis. Some of these workers reported their results as "mg.\% of total ketone bodies," to which our figures may be converted by multiplying by the factor 1.85 . We have avoided this method of expression because the exact value of this factor varies according to the proportions of the three ketone bodies present in each sample, which may fluctuate.

The results obtained from blood samples of nine determinations on healthy volunteers are tabulated in Table I. Their moods, thoughts, and activities were assessed at the time and also re- viewed later. All were relatively calm, secure, and happy at the time. The greatest difference between any two consecutive determinations of ketones on one subject was $0.3 \mathrm{mg} . \%$, which was also the greatest difference between any two determinations on the same subject in the same morning. In subjects whose ketones were measured before and one hour after meals, postprandial falls of from 0.3 to $1.0 \mathrm{mg} . \%$ were observed. This is in accord with the finding of Somogyi that the blood ketone level falls one to three hours after a meal $(29,30)$.

Blood glucose levels studied on three of these subjects varied as much as $14 \mathrm{mg}$.\% between consecutive determinations. The greatest total fluctuation during a morning was $15 \mathrm{mg} . \%$. Others have also observed such fluctuations $(31,32)$.

TABLE II

Non-diabetic subjects: reactions during stress

\begin{tabular}{|c|c|c|c|c|c|c|c|c|}
\hline \multirow{2}{*}{ Subject } & \multirow{2}{*}{$\begin{array}{l}\text { Sex, } \\
\text { age }\end{array}$} & \multirow{2}{*}{ Situation } & \multicolumn{3}{|c|}{ Blood ketones, mg. \%* } & \multicolumn{3}{|c|}{ Blood glucose, $m g . \%^{*}$} \\
\hline & & & 1 st hr. & 2nd hr. & 3rd hr. & 1st hr. & 2nd hr. & $3 \mathrm{rd} \mathrm{hr}$. \\
\hline $\mathrm{E}$ & M. 35 & $\begin{array}{l}\text { Suppressed anger during profes- } \\
\text { sional conference }\end{array}$ & 1.0 & 2.1 & 2.1 & 51 & 63 & 59 \\
\hline D & F. 23 & $\begin{array}{l}\text { Conflicting orders from superiors; } \\
\text { suppressed anger and fear }\end{array}$ & 2.0 & $2.4 \dagger$ & 1.1 & 70 & $104 \dagger$ & 60 \\
\hline $\begin{array}{l}F \\
G \\
H\end{array}$ & $\begin{array}{l}\text { F. } 45 \\
\text { F. } 28 \\
\text { F. } 27\end{array}$ & $\begin{array}{l}\text { Interview: conflict with mother } \\
\text { Interview: inability to get married } \\
\text { Interview: conflict with mother. In- } \\
\text { fidelity to husband }\end{array}$ & $\begin{array}{l}1.4 \\
2.1 \\
0.2\end{array}$ & $\begin{array}{l}3.5 \\
2.9 \\
1.8\end{array}$ & $\begin{array}{l}1.3 \\
2.2 \\
0.3\end{array}$ & $\begin{array}{l}72 \\
78 \\
80\end{array}$ & $\begin{array}{l}65 \\
84 \\
68\end{array}$ & $\begin{array}{l}63 \\
85 \\
44\end{array}$ \\
\hline AW & M. 50 & $\begin{array}{l}\text { Interview: fear of having another } \\
\text { coronary occlusion }\end{array}$ & 0.9 & 3.1 & 0.4 & 57 & 51 & 56 \\
\hline $\mathrm{AX}$ & F. 45 & $\begin{array}{l}\text { Interview: suppressing anxiety about } \\
\text { her health }\end{array}$ & 2.5 & 3.4 & 2.7 & 50 & 44 & 54 \\
\hline
\end{tabular}

* Values obtained during stress are in bold type. Subjects D, G, and AX were under stress at the time of the first sample.

$\dagger$ Subject received $100 \mathrm{gm}$. glucose P.O. one hour before this sample. 
M.E., M., 31 YRs. (WON-DIABe TIC)

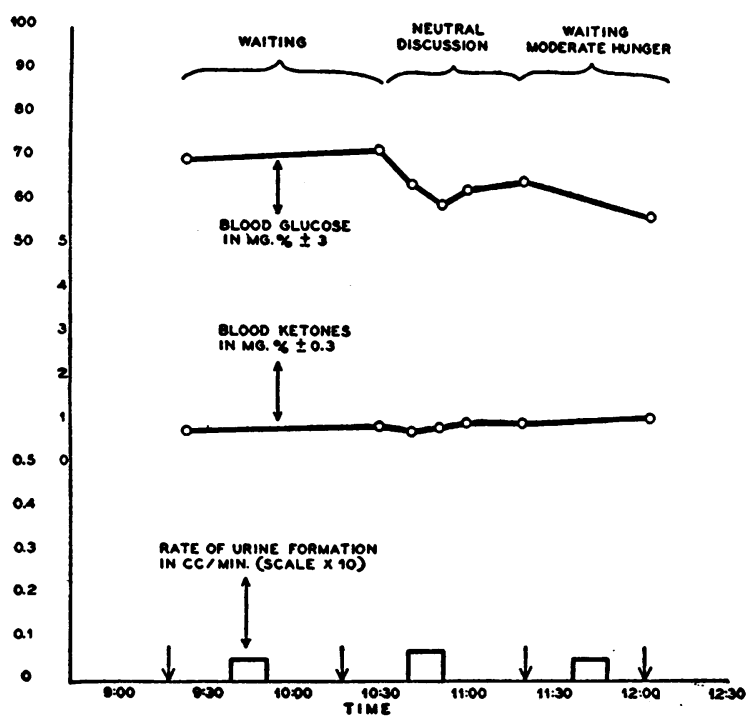

Fig. 1. Diagram of a Control Study on a NonDiabetic Subject, Demonstrating the Relatively Constant Concentration of Blood Ketones, and Minor Fluctuations in the Level of the Blood GLUCose

In Figure 1 is illustrated graphically the complete protocol of the experiment of Subject C, one of this group. The interview procedure was similar to that of the other diabetic and non-diabetic subjects, except that the discussion dealt with neutral topics and was not interpreted by the subject as threatening. He showed no significant change in blood ketones, blood sugar, or in urine output, during frequent sampling.

\section{Non-diabetic subjects under stress}

In Table II are shown the results obtained from experiments with non-diabetic subjects during stress. Two of the subjects who had been studied under more neutral circumstances were included in this group.

Subject $E$ was a young, enthusiastic, harddriving physician. Having only a light breakfast and no lunch, he attended a conference at which uninformed persons asked him what he regarded as stupid and unnecessary questions for more than an hour. He became moderately angry at his questioners and the delay they caused him, but felt unwilling to express his feelings toward them.
Subject D was a young, meticulous, conscientious chemist, who took pride in her work. She came to the laboratory after an overnight fast and was told by two of her superiors to perform two separate and difficult procedures. She felt angry at the request and afraid that she would not achieve her usual standard of performance, but she could not express her feelings. During the morning she was tense, with cold, moist palms, and she broke several pieces of glassware. In mid-morning she was allowed to drink $200 \mathrm{cc}$. of glucose flavored with citric acid. Shortly afterward a third superior demanded an immediate result from a third timeconsuming procedure. She was "furious inside." One hour after she drank the glucose her ketones had risen above the fasting level instead of falling as might have been expected. Later, as her superiors mitigated their demands, the ketone level fell.

The other five non-diabetic persons were examined during interviews in which threatening

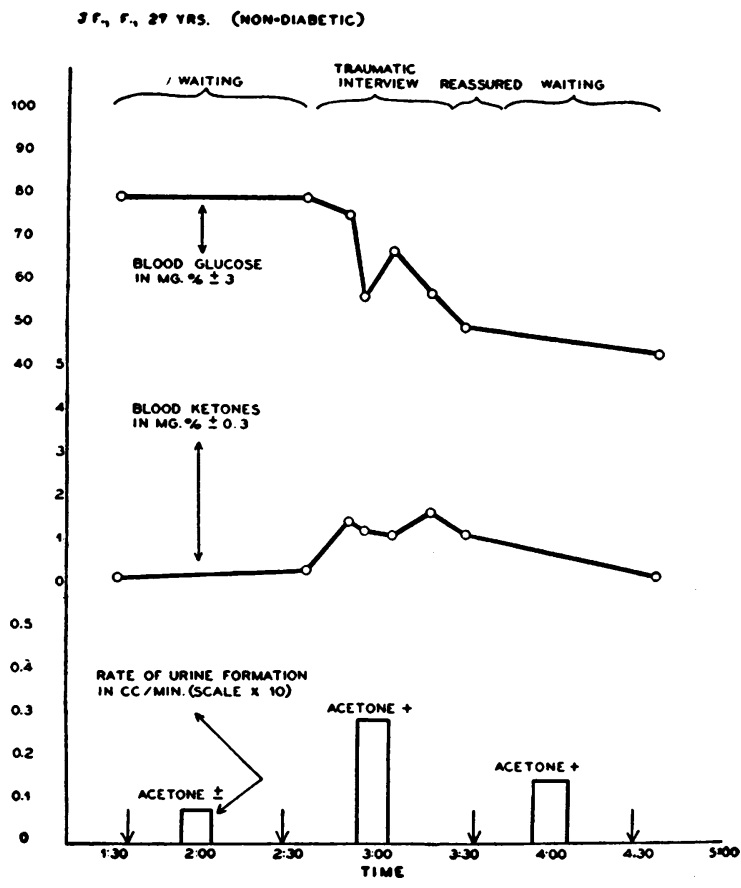

Fig. 2. The Effect of a Stressful Interview on the Level of the Blood Glucose and Ketones of a Non-Diabetic Subject

Under stress the subject developed a rise in ketones and a fall in blood sugar; when the stress was removed the ketones returned to their former level, but the glucose did not. Note the sharp rise in urine output during the period of stress. 
TABLE III

Diabetic subjects, initial ketone level below $1.5 \mathrm{mg} . \%$ : control studies

\begin{tabular}{|c|c|c|c|c|c|c|c|c|c|}
\hline \multirow{2}{*}{ Subject } & \multirow{2}{*}{$\begin{array}{l}\text { Sex, } \\
\text { age }\end{array}$} & \multirow{2}{*}{$\begin{array}{c}\text { Insulin } \\
\text { required } \\
\text { daily }\end{array}$} & \multirow{2}{*}{ Situation } & \multicolumn{3}{|c|}{ Blood ketones, mg. \% } & \multicolumn{3}{|c|}{ Blood glucose, mg. \% } \\
\hline & & & & 1st hr. & 2nd hr. & 3rd hr. & 1st hr. & 2nd hr. & 3rd hr. \\
\hline $\begin{array}{l}I \\
\mathbf{J} \\
\mathbf{L} \\
\mathbf{L} \\
\mathbf{P} \\
\mathrm{R}\end{array}$ & $\begin{array}{l}\text { M. } 15 \\
\text { F. } 42 \\
\text { M. } 29 \\
\text { F. } 50 \\
\text { M. } 16 \\
\text { F. } 21\end{array}$ & $\begin{array}{l}50 \mathrm{u} . \\
10 \mathrm{u} . \\
110 \mathrm{u} . \\
\text { Diet only } \\
50 \mathrm{u} . \\
40 \mathrm{u} .\end{array}$ & $\begin{array}{l}\text { Neutral interview } \\
\text { Neutral interview } \\
\text { Neutral interview } \\
\text { Neutral interview } \\
\text { Neutral interview } \\
\text { Neutral interview }\end{array}$ & $\begin{array}{l}1.1 \\
0.3 \\
0.8 \\
1.3 \\
1.3 \\
0.0\end{array}$ & $\begin{array}{l}1.3 \\
0.5 \\
1.1 \\
0.9 \\
1.5 \\
0.3\end{array}$ & $\begin{array}{l}0.3 \\
0.5 \\
0.7 \\
0.7 \\
2.4^{*} \\
0.3\end{array}$ & $\begin{array}{r}53 \\
120 \\
67 \\
100 \\
134 \\
268\end{array}$ & $\begin{array}{r}57 \\
124 \\
65 \\
97 \\
127 \\
256\end{array}$ & $\begin{array}{r}52 \\
110 \\
68 \\
100 \\
116 \\
235\end{array}$ \\
\hline
\end{tabular}

* Intense hunger during third hour

topics were discussed. The data are presented in tabular form in Table II. Figure 2 represents the complete protocol of case $\mathrm{H}$, from this group.

On the upper half of Figure 3 are represented the changes in the ketone bodies of the non-diabetic subjects under stress. On the lower half are shown the data from the control procedures. In all of the curves, including the controls, the second hour value represents the highest level attained during the interview period, while the other

NON-DIABETIC SUBJECTS

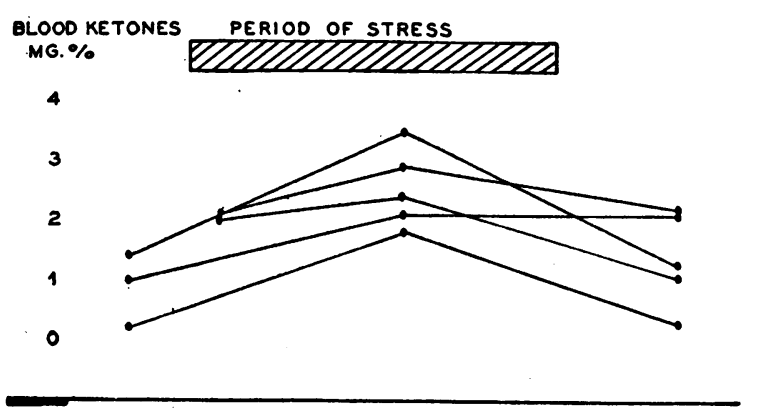

CONTROL STUDIES

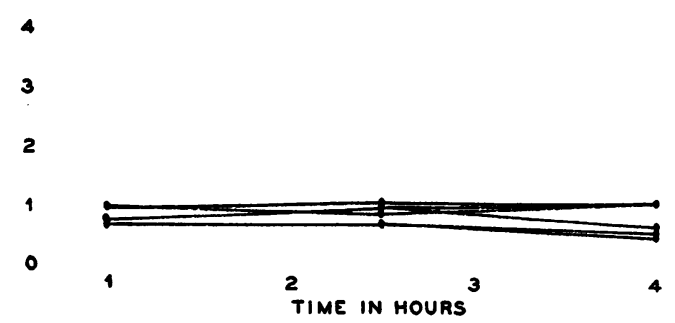

Fig. 3. Non-Diabetic Subjects: Composite Graph, Illustrating Changes in Blood Ketones During Stress (Above) and Control Studies (Below)

(Data from Subjects AW and AX in Table II are not included.) two values were obtained from the first and last samples drawn. It may readily be seen that in all of the persons subjected to stressful situations a rise in the ketones occurred, and that this was followed by a return to a lower level in those cases in which the stress was subsequently withdrawn. In the control studies, on the other hand, such changes did not take place, and the curves are flat.

It may be seen in Table II that although the glucose level cannot be said to have fluctuated predictably under stress, it does appear to have fluctuated more than under control conditions. However, the average deviations of successive samples in the control group $(4 \pm 1)$ and in the stress group $(7 \pm 3)$ were not significantly different in this small number of cases. Other workers have observed modest elevations of blood glucose to approximately $120 \mathrm{mg} . \%$ in fasting non-diabetic persons under circumstances of stress (33-35). Moreover in aviators prior to combat missions (33) values as high as $180 \mathrm{mg} . \%$ have been reported, suggesting that the duration and magnitude of the stressful stimulus may be important in determining the level attained. On the other hand hypoglycemic reactions have also been observed in normal persons who were vigorously suppressing emotional conflicts (36). The small group of normal subjects studied here did not include any who developed significant hyperglycemia, but it may be seen that two subjects developed a moderate hypoglycemia while suppressing fear.

\section{DIABETIC SUBJECTS : RESULTS}

Initial ketone level below $1.5 \mathrm{mg} . \%$ : control studies

In Table III are shown the results of control studies on diabetic subjects whose initial blood 
ketone level was less than $1.5 \mathrm{mg} . \%$. It has been pointed out that in non-diabetic persons under no significant stress, $1.5 \mathrm{mg} . \%$ appeared to be the greatest concentration of ketone bodies found in the blood in the morning after an overnight fast. This concentration was therefore arbitrarily set as the upper limit of normal under the conditions of our experiments. It may be seen from the table, and also from the protocol of one of these experiments which is diagrammed in Figure 4, that the ketone level of diabetic subjects whose initial level was within this normal range at the outset of the experiment did not fluctuate significantly if it was possible to maintain them in a reasonably comfortable and neutral state throughout a morning. The blood glucose level also remained relatively stable, but fluctuations were greater than those of the ketones.

\section{Diabetic subjects under stress, initial ketone level below $1.5 \mathrm{mg} . \%$}

In Table IV, are tabulated the experimental findings during the emotionally charged interviews in this group of diabetic subjects. In every case the blood ketones rose during the interview and then fell to lower levels when the stress was withdrawn. It may be seen that in many cases the concentration rose well above $1.5 \mathrm{mg} . \%$, returning with reassurance and diversion to levels below this figure. The blood glucose fluctuated widely during the stress procedures, changing as much as $125 \mathrm{mg} . \%$ in ten minutes in Subject O. The blood glucose and ketones, however, did not necessarily change in the same direction.

Figure 5 represents the complete protocol of stressful interview with Subject $P$, from this group, the 15-year-old son of an alcoholic busdriver. The interview aroused in him sullen resentment toward both his father and the interviewer. The ketone level rose abruptly as the interview began, and did not subside even after $0.2 \mathrm{gm}$. of sodium amytal administered intravenously had produced some degree of relaxation in him; however, as soon as more reassuring topics were discussed a prompt fall occurred. The general trend of the blood glucose was downward throughout the interview, but there were marked fluctuations.

Figure 6 represents the protocol of a three-hour observation on a 52-year-old single woman who had contracted diabetes in association with mild depressive symptoms following the death of her mother ten years before. Since then she had lived alone and frequently ruminated about her mother.

TABLE IV

Diabetic subjects, initial ketone level below $1.5 \mathrm{mg} . \%$ : changes during stressful interviews

\begin{tabular}{|c|c|c|c|c|c|c|c|c|c|}
\hline \multirow{2}{*}{ Subject } & \multirow{2}{*}{$\begin{array}{l}\text { Sex, } \\
\text { age }\end{array}$} & \multirow{2}{*}{$\begin{array}{l}\text { Insulin } \\
\text { required } \\
\text { daily }\end{array}$} & \multirow{2}{*}{$\begin{array}{c}\text { Situation } \\
\text { (interview topic) }\end{array}$} & \multicolumn{3}{|c|}{ Blood ketones, mg. \%† } & \multicolumn{3}{|c|}{ Blood glucose, mg. \%† } \\
\hline & & & & 1st hr. & 2nd hr. & $3 r d \mathrm{hr}$. & 1st hr. & 2nd hr. & 3rd hr. \\
\hline $\begin{array}{l}\mathbf{I} \\
\mathbf{K} \\
\mathbf{J} \\
\mathbf{M}\end{array}$ & $\begin{array}{l}\text { M. } 15 \\
\text { M. } 29 \\
\text { F. } 42 \\
\text { M. } 45\end{array}$ & $\begin{aligned} 50 \mathrm{u} \\
110 \mathrm{u} . \\
10 \mathrm{u} . \\
10 \mathrm{u} .\end{aligned}$ & $\begin{array}{l}\text { am. *Parent's arguments } \\
\text { His "failure in life" } \\
\text { am. Infidelity of husband } \\
\text { Wife's scorn for his impo- } \\
\text { tence }\end{array}$ & $\begin{array}{l}0.2 \\
0.9 \\
0.2 \\
1.4\end{array}$ & $\begin{array}{l}1.6 \\
1.4 \\
1.6 \\
2.6\end{array}$ & $\begin{array}{l}0.3 \\
0.6 \\
0.2 \\
0.7\end{array}$ & $\begin{array}{l}212 \\
195 \\
186 \\
193\end{array}$ & $\begin{array}{l}199 \\
209 \\
189 \\
233\end{array}$ & $\begin{array}{l}140 \\
205 \\
173 \\
175\end{array}$ \\
\hline $\mathbf{N}$ & F. 55 & 10 u. & $\begin{array}{l}\text { Mother's death; loneli- } \\
\text { ness, jobless }\end{array}$ & 0.7 & 2.0 & 1.3 & 174 & 180 & 172 \\
\hline $\mathbf{0}$ & F. 18 & $80 \mathrm{u}$. & $\begin{array}{l}a m \text {. Hostility to inter- } \\
\text { viewer }\end{array}$ & 0.9 & 1.6 & 0.2 & 183 & 275 & 193 \\
\hline $\mathbf{P}$ & M. 15 & $60 \mathrm{u}$. & $\begin{array}{l}\text { am. Parent's conflict } \\
\text { Father's brutality }\end{array}$ & 0.9 & 4.2 & 1.3 & 290 & 276 & 223 \\
\hline $\begin{array}{l}\text { Q } \\
\text { R } \\
\text { V } \\
\text { AC } \\
\text { AC } \\
\text { AB }\end{array}$ & $\begin{array}{l}\text { F. } 14 \\
\text { F. } 21 \\
\text { F. } 35 \\
\text { F. } 52 \\
\text { F. } 52 \\
\text { M. } 50\end{array}$ & $\begin{array}{l}60 \mathrm{u} . \\
40 \mathrm{u} . \\
40 \mathrm{u} . \\
45 \mathrm{u} . \\
45 \mathrm{u} . \\
28 \mathrm{u} .\end{array}$ & $\begin{array}{l}\text { Conflict with mother } \\
\text { Conflict with mother } \\
\text { Husband's drunkenness } \\
\text { Conflict with neighbors } \\
\text { Mother's death } \\
\text { Simulated venous cathe- } \\
\text { terization }\end{array}$ & $\begin{array}{l}\overline{1.4} \\
0.2 \\
0.9 \\
0.6 \\
0.7\end{array}$ & $\begin{array}{l}-\overline{3.6} \\
1.2 \\
1.8 \\
2.0 \\
2.6\end{array}$ & $\begin{array}{l}-\overline{1.6} \\
0.6 \\
0.7 \\
0.3 \\
0.6\end{array}$ & $\begin{array}{r}135 \\
280 \\
83 \\
96 \\
86 \\
133\end{array}$ & $\begin{array}{r}178 \\
285 \\
74 \\
78 \\
114 \\
103\end{array}$ & $\begin{array}{r}140 \\
212 \\
71 \\
99 \\
87 \\
109\end{array}$ \\
\hline $\begin{array}{l}\mathrm{AI} \\
\mathrm{BC}\end{array}$ & $\begin{array}{l}\text { F. } 52 \\
\text { F. } 17\end{array}$ & $\begin{array}{l}30 \mathrm{u} . \\
75 \mathrm{u} .\end{array}$ & $\begin{array}{l}\text { Son's drunkenness } \\
\text { Conflict with parents }\end{array}$ & $\begin{array}{l}0.4 \\
0.4\end{array}$ & $\begin{array}{l}2.1 \\
2.5\end{array}$ & $\begin{array}{l}0.9 \\
0.2\end{array}$ & $\begin{array}{r}154 \\
95\end{array}$ & $\begin{array}{r}143 \\
94\end{array}$ & $\begin{array}{r}144 \\
79\end{array}$ \\
\hline
\end{tabular}

* am.-Patient received sodium amytal.

$\dagger$ Values in bold type are those obtained during stress. 
(J) F. 42 YR. (10 UNITS INSUUN)
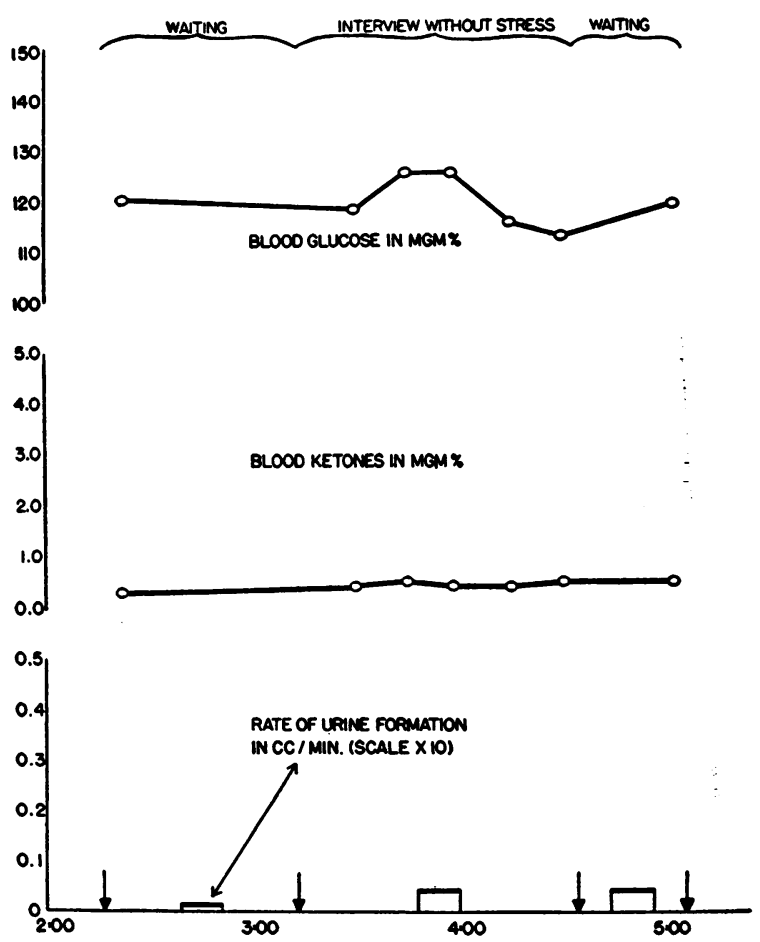

Fig. 4. Diagram of a Control Study on a Diabetic Subject Whose Initial Ketone Level. Was Below 1.5 mg.\%, Demonstrating the Relative Stability of the Blood Ketone Level in the Absence of Special Stimuli

The glucose level shows a somewhat greater tendency to fluctuate.

She was familiar with the experimental procedure and felt secure in the presence of the interviewer. While he sat at a desk nearby she lay quietly upon the examining table with her eyes half closed and a sad, distant expression upon her face. When asked about what she was thinking she replied, "My mother. I always think of her. I feel so sad and lonely when I do." The investigator, through his knowledge of her personality, felt that these thoughts were stressful to her. Accordingly he began a lively conversation which was calculated to reassure and divert her. Thereupon she became evidently more cheerful. The ketone level, which had risen in the fourth, fifth, and sixth samples drawn during her unhappy ruminations, fell as she was reassured and diverted from her morbid thoughts. In this experiment the rise in ketones was accompanied by a rise in blood sugar. It is also noteworthy that the increases in ketones and blood sugar were accompanied by a fall in the circulating eosinophiles, and that the eosinophiles returned toward their former level as the ketone and glucose elevations subsided. The relationship between blood ketones and the circulating eosinophiles of diabetic persons will be described and discussed in a subsequent paper (37).

Figure 7 is a composite graph in which the ketone levels throughout the control procedures may be compared with those observed during the stressful interviews in this group of diabetics.

\section{Diabetic subjects, initial ketone level above 1.5 $m g . \%$ : Control Studies}

In some of the diabetic subjects the blood ketones were elevated at the time of their arrival for the experiments. Table $\mathrm{V}$ shows the result of

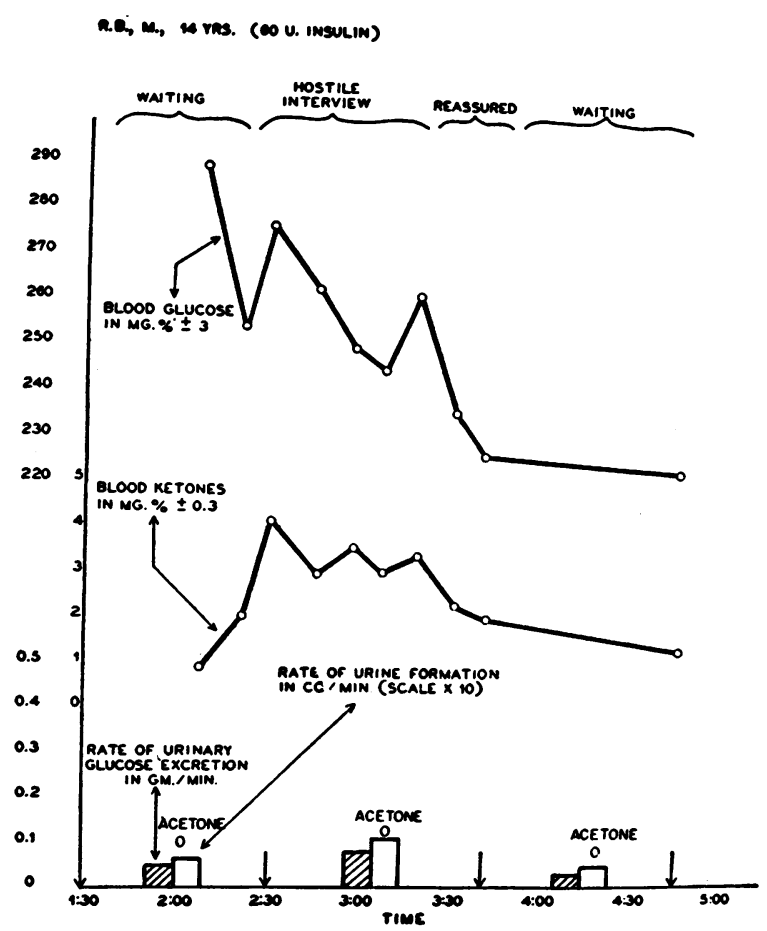

Fig. 5. The Effect of a Stressful Interview upon a Diabetic Subject Whose Initial Ketone Level Was LESS THAN 1.5 MG.\%

The ketones rose markedly during the interview, and fell during reassurance. The glucose level fluctuated widely, fell $70 \mathrm{mg} . \%$ during the interview, and then leveled off during the final control hour. In this case the increase in urine output was relatively small, but in other experiments much larger increases were noted. 
TABLE V

Diabetic subjects, initial ketone levels above $1.5 \mathrm{mg} . \%$ : control studies

\begin{tabular}{|c|c|c|c|c|c|c|c|c|c|}
\hline \multirow{2}{*}{ Subject } & \multirow{2}{*}{ Sex, age } & \multirow{2}{*}{$\begin{array}{l}\text { Insulin } \\
\text { required } \\
\text { daily }\end{array}$} & \multirow{2}{*}{ Situation } & \multicolumn{3}{|c|}{ Blood ketones, $m g . \%$} & \multicolumn{3}{|c|}{ Blood glucose, mg.\% } \\
\hline & & & & 1st hr. & 2nd hr. & $3 \mathrm{rd} \mathrm{hr}$. & 1st hr. & 2nd hr. & $3 \mathrm{rd} \mathrm{hr}$. \\
\hline $\begin{array}{l}T \\
\mathbf{U} \\
\mathbf{V} \\
\mathbf{Y} \\
\mathbf{I} \\
\mathbf{U}\end{array}$ & $\begin{array}{l}\text { M. } 55 \\
\text { F. } 20 \\
\text { F. } 35 \\
\text { F. } 16 \\
\text { M. } 15 \\
\text { F. } 20\end{array}$ & $\begin{array}{c}\text { Diet only } \\
100 \mathrm{u} . \\
40 \mathrm{u} . \\
90 \mathrm{u} . \\
50 \mathrm{u} . \\
100 \mathrm{u} .\end{array}$ & $\begin{array}{l}\text { Neutral interview } \\
\text { Neutral interview } \\
\text { Neutral interview } \\
\text { Neutral interview } \\
\text { Neutral interview } \\
\text { Neutral interview }\end{array}$ & $\begin{array}{l}3.7 \\
2.7 \\
4.7 \\
5.3 \\
1.5 \\
3.2\end{array}$ & $\begin{array}{l}4.1 \\
2.6 \\
5.3 \\
7.5 \\
1.9 \\
3.9\end{array}$ & $\begin{array}{l}3.5 \\
2.4 \\
6.0 \\
8.5 \\
1.4 \\
3.2\end{array}$ & $\begin{array}{r}153 \\
175 \\
283 \\
240 \\
286 \\
65\end{array}$ & $\begin{array}{r}150 \\
172 \\
284 \\
273 \\
291 \\
70\end{array}$ & $\begin{array}{r}151 \\
125 \\
261 \\
227 \\
271 \\
73\end{array}$ \\
\hline
\end{tabular}

neutral interviews in six such cases. The ketone levels of three of the subjects rose gradually throughout the morning, and fluctuations were greater than those seen in patients whose initial ketone levels were within the normal range; but in the absence of special stimuli no wide fluctuations were observed. The glucose fluctuations

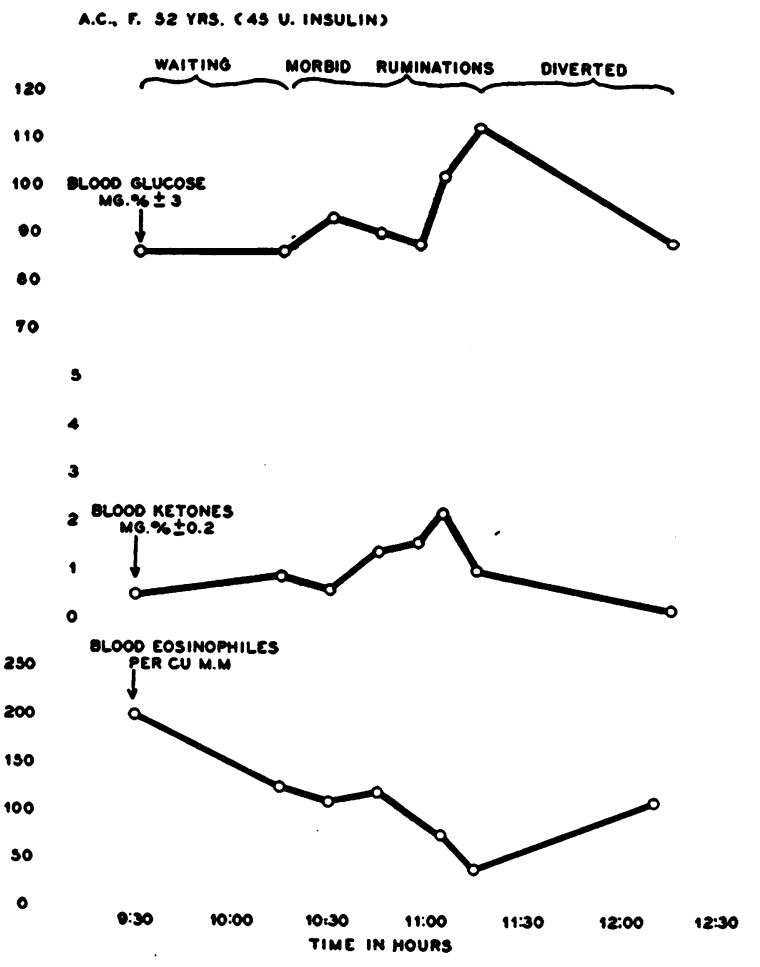

Fig. 6. Changes During Recollection and "ReLIving" of Incidents Surrounding Mother's Death

Diabetic subject whose initial ketone level was less than $1.5 \mathrm{mg} . \%$. In this experiment the rise in the ketones was associated with a rise in blood glucose. The fall in circulating eosinophiles which took place as the ketones rose has also been found in other cases. Ketones, glucose, and eosinophiles all returned toward their initial levels as the patient was diverted. were of much larger magnitude than were the fluctuations in circulating ketone bodies. Figure 8 illustrates the protocol of one of these studies (Subject U).

\section{Diabetic subjects under stress, initial ketone levels above $1.5 \mathrm{mg} . \%$}

Table VI illustrates the results of stressful interviews with six subjects whose initial ketone levels

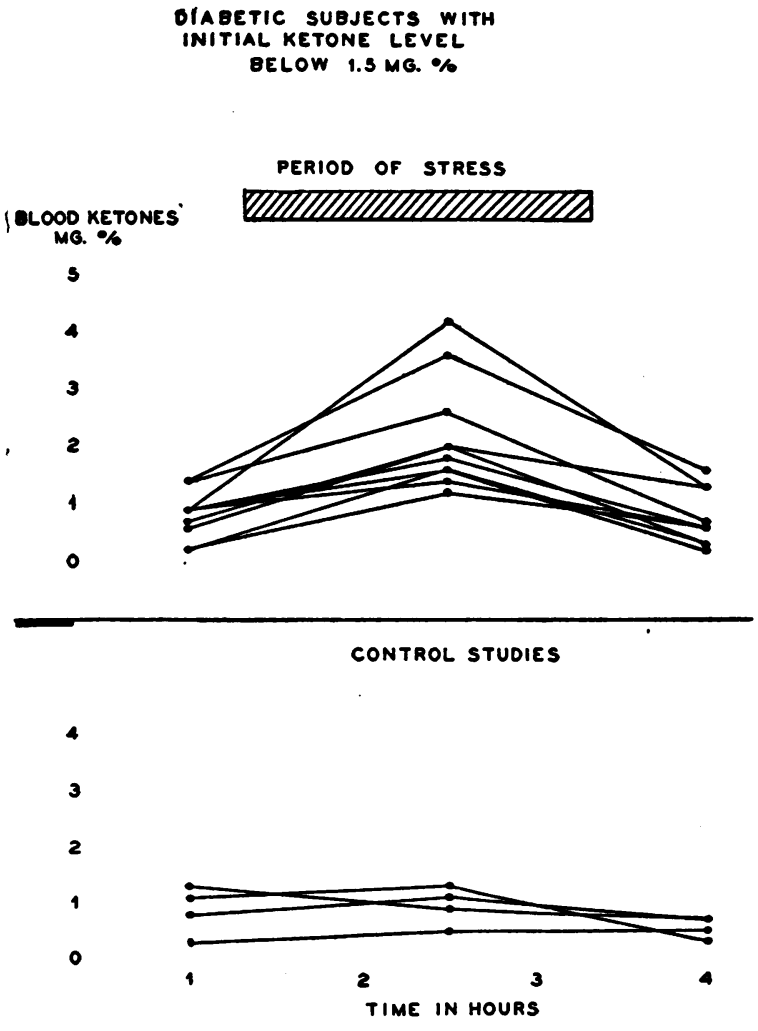

Fig. 7. Diabetic Subjects, Initial Ketone Levels Below 1.5 Mg.\%, Composite Graph, Showing the Changes During Stress (Above) and Control StudiES (Below) ON BloOd Ketones 


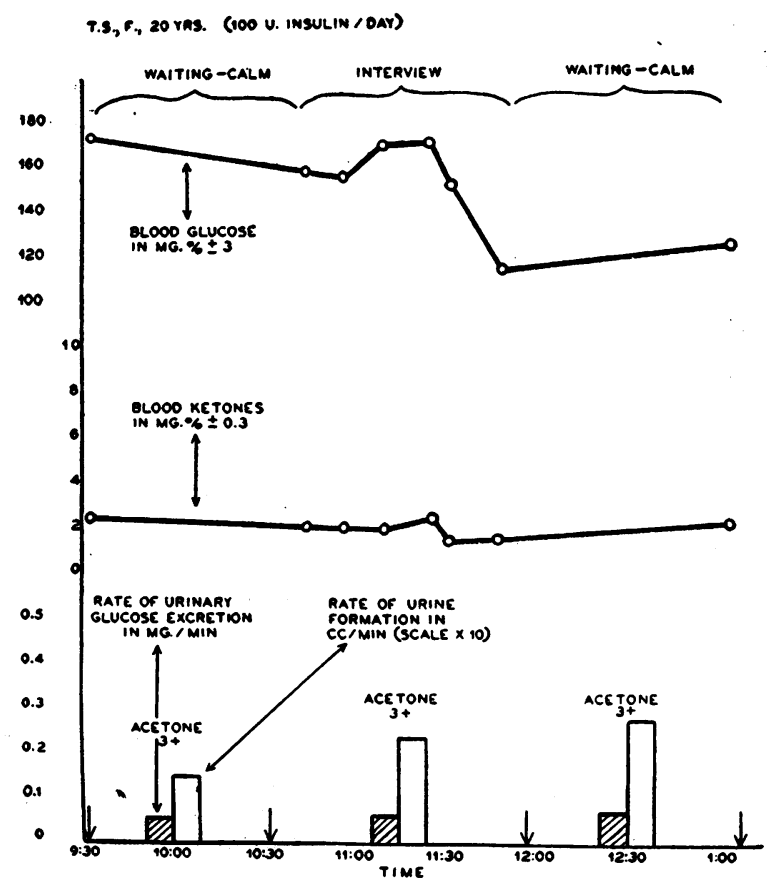

Fig. 8. Diagram of a Control Study on a Diabetic Subject Whose Initial Ketone Level Was Higher Than 1.5 Mg.\%, Demonstrating a Relative Stability of the Blood Ketones in the Absence of Special Stimuli

The fluctuations of blood glucose are relatively great.

were above $1.5 \mathrm{mg} . \%$. Rises in ketone concentration of relatively great magnitude occurred, with equally striking falls occurring during reassurance. In this Table it will be noted that although the high values for ketones usually occurred during the middle of the experimental procedure, in the first experiment on Subject $Y$, when she was tense, apprehensive, and depressed at the time the initial specimen was taken, the initial level was also high. The changes in glucose concentration, on the other hand, in these subjects were hardly of greater magnitude than those which occurred during the control procedure in which the patients were subjected to less trying circumstances.

Figure 9 represents the protocol of the stressful interview with Subject U, which may be compared to the control interview with this same subject shown in Figure 8. In every respect, except for the patient's attitude and the content and symbolism of the interview, the procedures were identical. During the control procedure the girl felt calm and secure with the physician, whom she knew well and liked; the topics they discussed were those which many interviews had shown to have only slight emotional or symbolic meaning to her. During the second interview, on the other hand, she was presented with a major threat. When she arrived the physician allowed her to gain the impression that she would be given sodium amytal, and that she might then be induced to reveal information which she had previously been unwilling to discuss. She was outwardly an innocent, pious girl but, as revealed in subsequent interviews, the thought that under the influence of sodium amytal she might disclose her voluminous erotic fantasies and homosexual feelings aroused intense anger, fear, and guilt within her. These feelings were intensified by reason of the fact that the physician was the object of many of her thoughts. Her conflict persisted with unabated intensity throughout the first waiting hour, and was

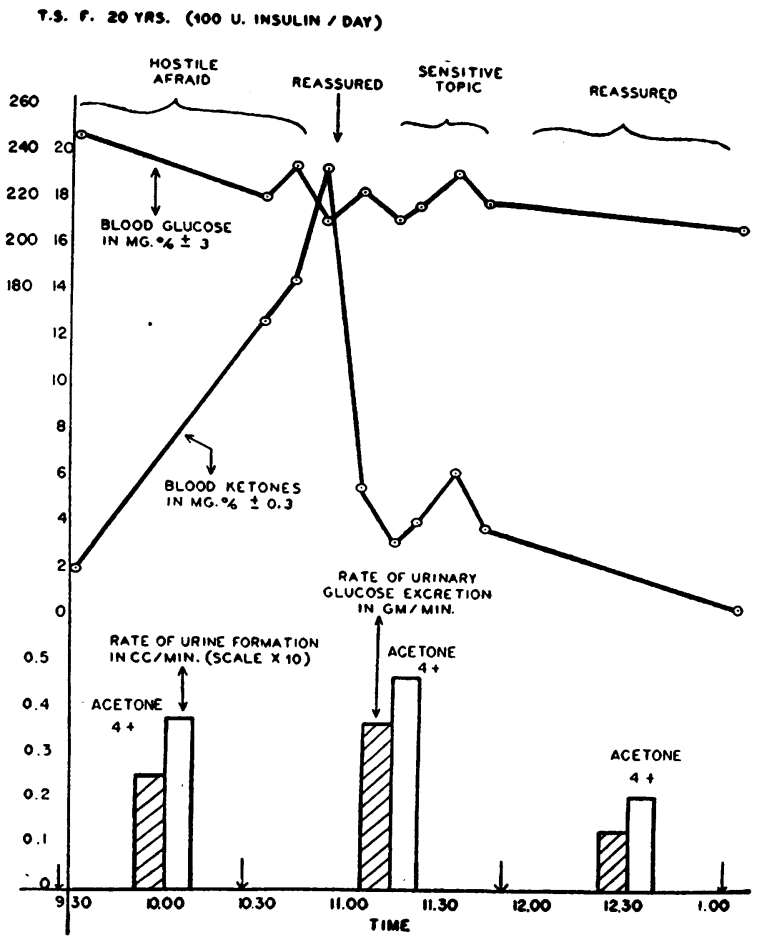

Fig. 9. The Effect of a Stressful Situation Upon a Diabetic Subject Whose Initial Ketone Level Was Higher Than $1.5 \mathrm{Mg} . \%$

A marked rise in the ketone level is evident during stress followed by an equally great fall with reassurance. The polyuria and glycosuria associated with the rise in blood ketones may be compared with that of the control study on the same subject, shown in Table VI. 
TABLE VI

Diabetic subjects, initial ketone level above $1.5 \mathrm{mg} . \%$ : effect of stressful interviews

\begin{tabular}{|c|c|c|c|c|c|c|c|c|c|}
\hline \multirow{2}{*}{ Subject } & \multirow{2}{*}{ Sex, age } & \multirow{2}{*}{$\begin{array}{l}\text { Insulin } \\
\text { required } \\
\text { daily }\end{array}$} & \multirow{2}{*}{$\underset{\text { (interview topic) }}{\text { Situation }}$} & \multicolumn{3}{|c|}{ Blood ketones, $m g . \% *$} & \multicolumn{3}{|c|}{ Blood glucose, $m g . \% *$} \\
\hline & & & & 1st hr. & 2nd hr. & 3 rd hr. & 1st hr. & 2nd hr. & $3 \mathbf{r d ~ h r}$ \\
\hline $\mathbf{U}$ & F. 20 & $100 \mathrm{u}$. & $\begin{array}{l}\text { Sexual fantasies; conflict } \\
\text { with mother }\end{array}$ & 2.1 & 19.6 & 0.7 & 248 & 237 & 215 \\
\hline$\stackrel{N}{\mathbf{W}}$ & $\begin{array}{l}\text { F. } 55 \\
\text { M. } 40\end{array}$ & $\begin{array}{l}10 \mathrm{u} . \\
\text { Diet only }\end{array}$ & $\begin{array}{l}\text { Hostility toward interviewer } \\
\text { Anger during attempt at ve- } \\
\text { nous catheterization }\end{array}$ & $\begin{array}{l}2.4 \\
1.8\end{array}$ & $\begin{array}{l}8.9 \\
7.5\end{array}$ & $\begin{array}{l}5.7 \\
5.5\end{array}$ & $\begin{array}{l}104 \\
200\end{array}$ & $\begin{array}{r}86 \\
199\end{array}$ & $\begin{array}{r}94 \\
152\end{array}$ \\
\hline $\begin{array}{l}\mathbf{Y} \\
\mathrm{AE} \\
\mathbf{Y}\end{array}$ & $\begin{array}{l}\text { F. } 16 \\
\text { M. } 35 \\
\text { F. } 16\end{array}$ & $\begin{array}{l}90 \mathrm{u} . \\
60 \mathrm{u} . \\
90 \mathrm{u} .\end{array}$ & $\begin{array}{l}\text { Conflict with mother } \\
\text { Conflict with employer } \\
\text { Rumination: conflict with } \\
\text { mother }\end{array}$ & $\begin{array}{l}7.6 \\
1.7 \\
1.5\end{array}$ & $\begin{array}{r}9.3 \\
14.7 \\
6.8\end{array}$ & $\begin{array}{l}5.9 \\
2.3 \\
2.1\end{array}$ & $\begin{array}{r}282 \\
91 \\
221\end{array}$ & $\begin{array}{l}274 \\
100 \\
208\end{array}$ & $\begin{array}{l}202 \\
101 \\
206\end{array}$ \\
\hline
\end{tabular}

* Values in bold type are those obtained during stress.

not dispelled until after the interview had begun, when the words and actions of the interviewer showed her that amytal would not be given after all. Her realization of this coincided with the abrupt fall in ketonemia. After a period of comparatively neutral discussion the topic was turned to her conflict with her overprotective, restrictive mother. Again a rise occurred. Finally the physician reassured her of his support and respect for her, turned to neutral topics, and allowed her to divert herself during the last hour. The blood ketones again fell.

Figure 10 is a composite graph, on which the ketone changes produced in this group of diabetics by stressful interviews may be compared with those which were obtained in a similar group of patients during control procedures. It may be seen, by comparing this graph with Table V, that the magnitude of the changes produced by stress in these subjects was much greater than those which occurred in patients whose initial ketone level was below $1.5 \mathrm{mg} . \%$.

\section{COMMENT}

Elsewhere is reported (38) the case of a diabetic girl in whom a moderately severe episode of keto-acidosis was precipitated by a conflict with her mother. She was under careful observation in the hospital at the time and her diet, insulin, and activity were maintained constant. The ketoacidosis subsided after strong reassurance without additional insulin or other change in therapy. Since then we have had the opportunity to observe two similar instances of ketosis occurring under stress in the relatively controlled hospital environment. The observations on this group of diabetic subjects-and especially upon Subject U-provide further evidence that the ketosis which may occur in association with conflict situations may rapidly lead to a severe acidosis, and even to coma.

The blood ketones during diabetic ketosis and coma usually range between 40 and $200 \mathrm{mg} . \%$ (39). Since, in Subject U, the ketones rose 17 mg.\% within an hour and a half, it seems possible that levels as high as these might have been reached after three and a half hours had the stimulus been maintained. Although the ketone bodies may not, in themselves, be the cause of coma, a high level of ketonemia with dehydration is a reliable indication of a diabetic decompensation in the direction of coma (40). Such a rapid induction of ketosis might explain such reports as that of Von Noorden (41) whose diabetic banker, previously well controlled, attended a stormy meeting of his board of directors, returned home, and shortly became comatose.

We have found that striking increases in the rate of urine formation and the rate of glucose excretion may be produced by the stressful stimuli which cause elevations of the blood ketone level. The urinary response to stress with its associated disturbance of body fluid and electrolyte balance is as important as the disturbance of fat and carbohydrate metabolism in its noxious effect upon the patient. Some of the observed changes in urine output have been included in the diagrams of the experiments. They are described at greater length elsewhere (13). 

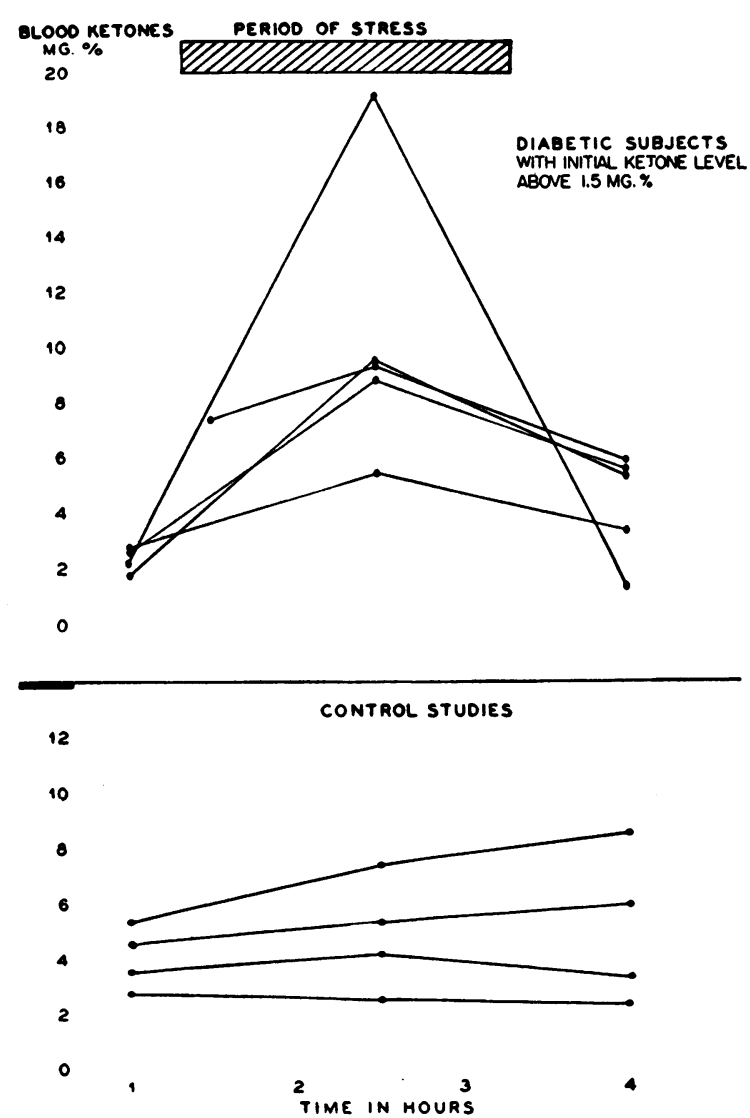

Fig. 10. Diabetic Subjects, Initial Ketone Level Above 1.5 Mg.\%: Composite Graph Illustrating Change in Blood Ketones During Stress (Above) and During Control Studies (Below)

(Data from Subject $I$ and the second experiment on Subject $U$ from Figure 8; and from Subject $A E$ and the second experiment on Subject Y, from Figure 9, are not included.)

\section{The amelioration of high level ketonemia without insulin}

In Figure 11 is reproduced the protocol of a second experiment on Subject $P$, when an attempt was made to produce a fall rather than a rise in blood ketones. This boy, in whom a rise in ketones had been produced from an initial normal level (Figure 5), and who had resented but tolerated the procedure, was called back peremptorily one month later for a second interview. He was sullen, resentful, and uncommunicative when he arrived. During the interview he was pleased and relieved to find the discussion limited to model airplanes and sports, two of the chief sources of pleasure in his drab life. When it ended he was smiling, talking freely, and feeling that the physician was an understanding friend. During the last hour of waiting he began to become hungry and bored, but remained much happier than before. The steady fall in ketone level during the interview was striking, A similar phenomenon was produced in a second subject, whose ketone level was $20.8 \mathrm{mg} . \%$ on arrival, but fell to $2.0 \mathrm{mg} . \%$ during a sympathetic and reassuring interview and remained near this level, rising to only $2.5 \mathrm{mg} . \%$ after the third hour.

\section{Changes in the hepatic venous blood}

It was felt that the changes described in the peripheral venous blood might be related either to ketone production or utilization. Since the liver is known to be the source of the blood ketones, one experiment was carried out while blood samples were obtained from a catheter introduced into the subject's hepatic vein (42). Several attempts were made before a suitable experiment could be performed, for it was found that although patients

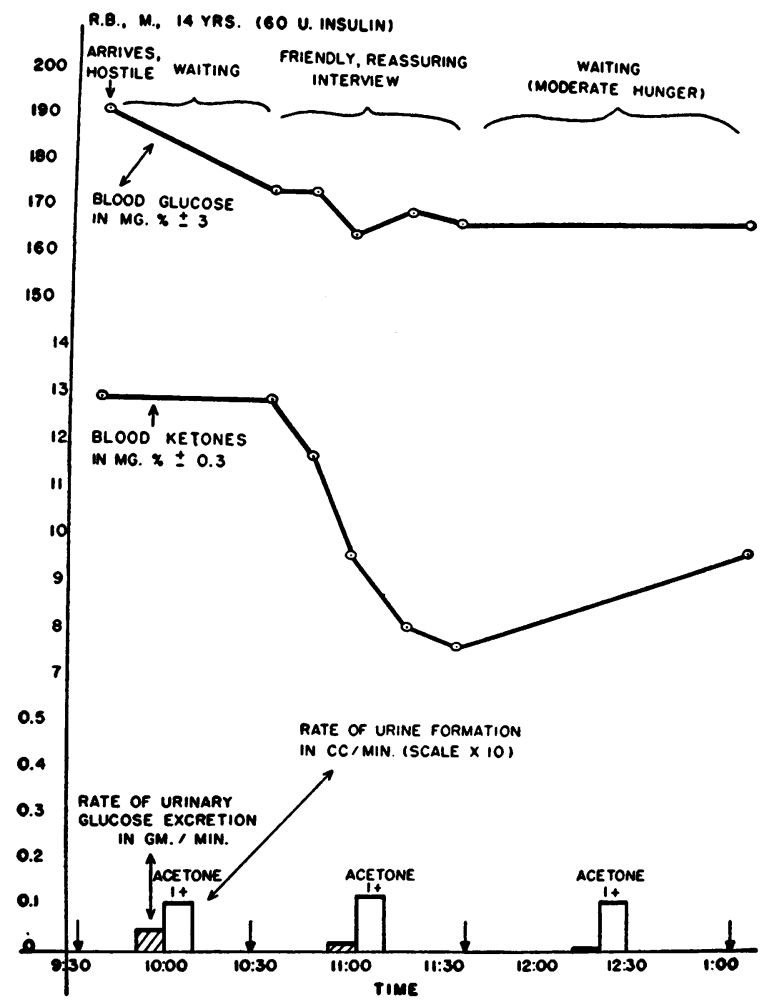

Fig. 11. The Amelioration of a Relatively High Level of Ketonemia by the Removal of Stress Through a Friendly and Reassuring Interview 


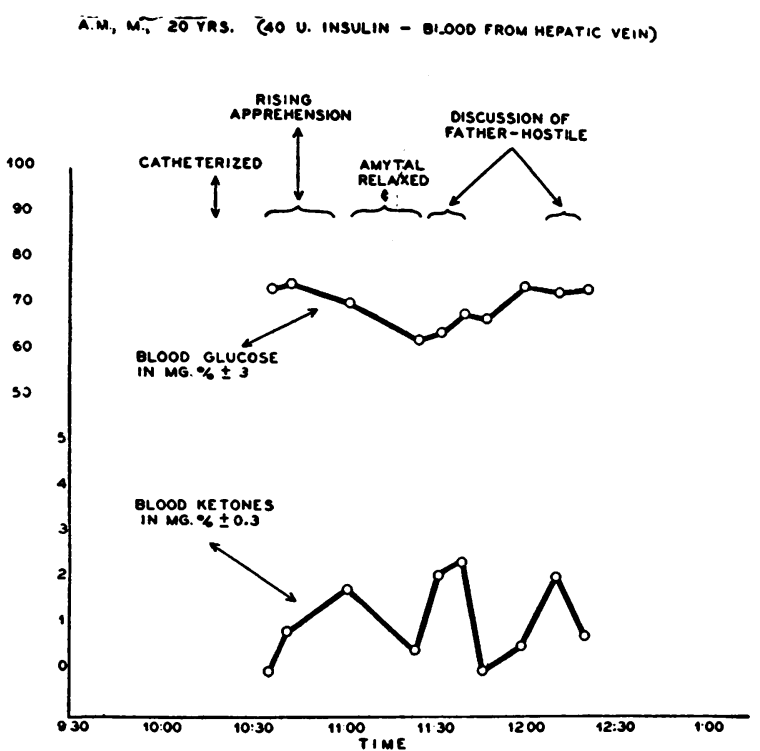

Fig. 12. Diagram Showing the Effect of an Interview Upon the Level of Ketones and Glucose in Blood Samples Obtained from the Hepatic Vein

A rapid rise in the ketones occurred each time a significant conflict was dwelt upon.

might remain outwardly calm and the true nature of the procedure might be concealed from them, they were all nevertheless aware that something "unusual and dangerous" was being done to them, and reacted with fear and resentment.

Figure 12 is the protocol of an interview with a 20-year-old college student (Subject $Z$ ) who had many doubts about his manliness, and felt resentful toward his tyrannical father. The initial ketone levels were less than $0.2 \mathrm{mg} . \%$ during relative relaxation, but when a discussion of manliness was undertaken a rapid increase in blood ketones to more than $2.0 \mathrm{mg} . \%$ was observed, and later, following a period of reassurance, sudden rises in ketones were twice induced during a discussion of his conflict with his father.

From these data it would appear that the changes in peripheral ketonemia may be at least in part produced by changes in ketone output by the liver.

\section{DISCUSSION}

It is known that the level of blood glucose in fasting diabetic subjects fluctuates widely (31, 43), and it has become apparent that their blood ketone bodies are labile also. It is therefore not possible to assign "normal" values for the blood ketones to a diabetic. Depending upon his previous diet, the length of time since he received insulin, his activity, and, apparently, his life situation, a diabetic may have either no detectable ketones or more than $10 \mathrm{mg} . \%$ in a fasting specimen on a "normal" morning. Although prolonged hypoglycemia is known to lead to ketonemia (44), within a wide range of values the blood glucose and ketones are quite independent of each other. In the morning fasting blood of patients without diabetic symptoms at the time, we have observed values of $38.0 \mathrm{mg} . \%$ of ketones when the blood sugar was $102 \mathrm{mg} . \%$, and $1.4 \mathrm{mg} . \%$ of ketones when the blood sugar was $342 \mathrm{mg} . \%$. A patient, without change in diet or insulin, on one morning had a blood sugar of $290 \mathrm{mg} . \%$ with $0.9 \mathrm{mg} . \%$ of ketones, and on another morning had a blood sugar of $192 \mathrm{mg} . \%$ with $13.0 \mathrm{mg} . \%$ of ketones. Briggs reported similar figures (45). However, it has been our general experience that diabetics who have none of the symptoms caused by either too much or too little insulin, and who are under no stress at the time, have blood ketone levels within the range of those found in the blood of non-diabetics under similar circumstances.

Like the blood glucose, the blood ketone bodies are a source of readily available body fuel. In all tissues except brain and testis they seem to constitute adequate sources of energy. When the diet is deficient in carbohydrates they appear in the blood in increasing amounts-possibly as a partial substitute for glucose, since aceto-acetate apparently may enter into the tri-carboxylic acid cycle, which is one of the steps through which glucose is converted into energy for muscle contraction (46). Ketonemia may also appear when there is an increased demand for metabolic fuel, such as occurs during fever (47) or after prolonged and vigorous exercise $(48-50)$. The data which have been presented here indicate that events in the life situation which either directly or through their symbolic meaning threaten the security and wellbeing of an individual may also call forth an increase in ketonemia. It is as if the perception of a threat led to a metabolic preparation to meet the threat. Such reactions in other bodily systems, such as the cardiovascular system, are well known $(51,52)$.

In some of the subjects there was sweating, 
tachycardia, and hyperpnea during the stress periods-clinical observations which suggest that in them there was at this time an increase in the over-all rate of metabolism, possibly associated with circulating adrenalin. But in others, such as Subject AC (Figure 6), these findings were absent; the pulse was slow, the skin warm and dry, and the subject outwardly quiet and relaxed. In other words, there was no clinical evidence of hypermetabolism at the time. It may be that the tense subjects were "mobilizing their available fuel in preparation for fight or flight," but this could hardly be said of the calm patients. We have conjectured that many of these subjects were reacting to the selected stimulus as if it represented a threat of starvation. The data obtained from the psychological studies of these patients offer unexpectedly strong support for this hypothesis, which is compatible with the available biochemical data. In later papers the evidence available in support of this concept will be discussed.

The increase in the level of the ketones of the peripheral venous blood under the stimulus of stress may represent either an increase in the production of ketones by the liver or a decrease in their utilization in the periphery, or both. The evidence from the single experiment with liver catheterization suggests that increased production by the liver is at least in part responsible for the phenomenon. Since there has been reported no circumstance in which the ability of the peripheral tissues to utilize ketones is depressed, it seems reasonable to assume that the entire phenomenon may be due to an increase in ketone production. There are two mechanisms kno̧wn through which stimuli arising in the central nervous system might effect an increase in ketone production. One is the elaboration of adrenalin through the stimulation of the adrenal medulla (53). The other is the elaboration of the hormones of the anterior pituitary and the adrenal as a primary effect of direct stimulation from the central nervous system through pathways as yet unknown. Both the growth hormone and the adrenocorticotrophic hormone of the pituitary stimulate ketogenesis (54), the former by direct action upon the liver, and the latter through its effect upon the adrenal cortex. The administration of 17-hydroxy-11dehydrocorticosterone (Compound $\mathrm{E}$ ) to a diabetic human has been associated with ketonuria and a decrease in the circulating eosinophiles $(55,56)$. A fall in the circulating eosinophiles has been taken to be evidence of the elaboration of adrenal cortical hormones (57). The fact that we have found the circulating eosinophiles to decrease as the blood ketone level rises in response to stressful situations therefore suggests that the adrenal cortex is involved in the mechanism by which the ketone changes are produced.

There is some evidence that fat and carbohydrate metabolism "compete" for the same enzyme systems in the liver (58). Therefore, it may be that persons whose blood ketones are already elevated have greater rises in response to stressful stimuli than those with normal ketone levels because they have an established ketone economy in their livers, and are capable of a greater immediate response.

By inspection of Tables IV and VI it may be seen that a variety of changes in the blood glucose took place during the stress experiments. Mirsky (59) has demonstrated experimentally that the reaction of a diabetic person to his life situation may be associated with hyperglycemia. Our studies confirm his findings. It would appear that hypoglycemic reactions may also occur in diabetic persons under separate and appropriate circumstances in reaction to stress. The data on blood glucose are included in this study for comparison with the ketone changes, and no conclusions are drawn from them at this time. In most cases we have observed the blood glucose to fall as the ketones rise in unfed individuals under stress. This subject is elaborated in detail elsewhere (14). It should be noted that the possibility of rapid and pronounced changes in the blood glucose must be taken into account in any attempt to evaluate the diabetic state from random estimations of blood sugar.

It has been pointed out that stressful situations may produce a rise in the blood ketones, and either a rise or a fall in the blood glucose. The ketones, which are normally present in only very small concentrations, may respond to a stimulus in only one of two ways : they may rise, or not rise. There is no opportunity for them to fall to an "abnormally low level" in the peripheral venous blood, because under normal circumstances no detectable ketones may be found there. The blood glucose, however, being maintained normally between 50 
and $80 \mathrm{mg} . \%$ by the various homeostatic mechanisms, may fall as well as rise in response to situational stimuli, or do both, or neither. One would expect that alternating or opposite reactions might occur, depending upon the situation presented and the patient's reaction to it, for we are accustomed to such double responses in other bodily systems. For example, in the examination of recruits for military service, it was not uncommon to find some men who reacted to the experience with tachycardia and an elevation of blood pressure, while others developed hypotension and fainted. Stevenson and Duncan (60) found that in patients with hypertension some stimuli produced marked elevations in the blood pressure, whereas stimuli having a different meaning for the patient and provoking a different response led to an equally marked fall. In persons with gastric symptoms some situations are associated with hypofunction and nausea, and others are associated with hyperfunction, hyperacidity, and pain (61). A similar phenomenon has been found in the large bowel (62), and the nasal mucous membrane (63), and it may well be found to be a characteristic of any bodily system which has the capacity for more than one type of reaction.

\section{CONCLUSIONS}

1. Stimuli arising out of the life experience of the individual and either consciously or unconsciously interpreted by him as threats to his security may produce in both diabetic and non-diabetic humans a rise in the ketone bodies in the venous blood, apparently because of increased production in the liver, and fluctuations in the blood sugar level.

2. The magnitude of the ketone elevations which were observed was much greater in diabetic persons than in non-diabetic persons. It seems probable that such changes, with accompanying changes in fluid balance, may, if sustained, lead to clinical acidosis, without the intervention of other factors such as intercurrent illness, changes in physical activity, or alteration of insulin or food intake.

3. Blood ketone levels which were elevated during stress subsided when relative emotional security was achieved, without extra insulin or other therapeutic manipulation.

4. The mechanism involved in these changes is not yet established but the evidence adduced in this study suggests that it involves a stimulation of the pituitary-adrenal mechanism.

\section{BIBLIOGRAPHY}

1. Conn, J. W., Louis, L. H., and Wheeler, C. E., Production of temporary diabetes mellitus in man with pituitary ACTH. Relation to uric acid metabolism. J. Lab. \& Clin. Med., 1948, 33, 651.

2. Selye, $H$., The general adaptation syndrome and the diseases of adaptation. J. Clin. Endocrinol., 1946, 6, 117.

3. Katz, S. E., A catatonic syndrome associated with diabetes mellitus. Arch. Neurol. \& Psychiat., 1934, 31, 880 .

4. Menninger, W. C., Inter-relationships of mental disorders and diabetes mellitus. J. Ment. Sc., 1935, 81, 332.

5. Menninger, W. C., Psychological factors in the etiology of diabetes. J. Nerv. \& Ment. Dis., 1935, 81, 1.

6. Daniels, G. E., Emotional and instinctual factors in diabetes mellitus. Am. J. Psychiat., 1936, 93, 711.

7. Daniels, G. E., Analysis of a case of neurosis with diabetes mellitus. Psychoanalyt. Quart., 1936, 5, 513.

8. Lindberg, B. J., Diabetic psychosis. Acta psychiat. et neurol., 1936, 11, 267.

9. Dunbar, F., Psychosomatic Diagnosis. Paul B. Hoeber, Inc., New York, 1943.

10. Meyer, A., Bollmeier, L. N., and Alexander, F., Correlation between emotions and carbohydrate metabolism in two cases of diabetes mellitus. Psychosom. Med., 1945, 7, 335.

11. Mirsky, I. A., Emotional factors in the patient with diabetes mellitus. Bull. Menninger Clinic, 1948, $12,187$.

12. Rosen, H., and Lidz, T., Emotional factors in the precipitation of recurrent diabetic acidosis. Psychosom. Med., 1949, 11, 211.

13. Hinkle, L. E., Wolf, S., and Edwards, C. J., Studies on diabetes mellitus: effects of stressful life situations upon the urine volume and glycosuria of diabetic and nondiabetic humans. (To be published)

14. Hinkle, L. E., and Wolf, S., Studies on diabetes mellitus: the effect of stressful life situations on the blood glucose of normal and diabetic persons. (To be published)

15. Hinkle, L. E., and Wolf, S., Studies on diabetes mellitus: the relation between stressful life situations and the occurrence of ketosis and coma in persons with diabetes mellitus. (To be published)

16. Hinkle, L. E., and Wolf, S., Studies on diabetes mellitus: observations on the situations in which hypoglycemic reactions occur in diabetic subjects. ( To be published)

17. Wolf, S., and Ripley, H. S., Studies on the action of intravenously administered sodium amytal. Am. J. M. Sc., 1948, 215, 56. 
18. Greenberg, L. A., and Lester, D., A micromethod for the determination of acetone and ketone bodies. J. Biol. Chem., 1944, 154, 177.

19. Lester, D., and Greenberg, L. A., The determination of acetone and ketone bodies. J. Biol. Chem., 1948, 174, 903.

20. Benedict, S. R., The determination of blood sugar. II. J. Biol. Chem., 1928, 76, 457.

21. Everett, M. R., Determination of sugar in blood. I. Observations upon Benedict's alkaline copper solution. J. Biol. Chem., 1929, 82, 369.

22. Benedict, S. R., The determination of sugar in blood. J. Biol. Chem., 1929, 83, 165.

23. Haden, R. L., A modification of the Folin-Wu method for making protein-free blood filtrates. J. Biol. Chem., 1923, 56, 469.

24a. Herbert, F. K., and Bourne, M. C., The non-sugar reducing substances of human blood, with special reference to glutathione. Biochem. J., 1930, 24, 299.

b. Herbert, F. K., and Bourne, M. C., The non-sugar reducing substances of human blood in pathological conditions. Biochem. J., 1930, 24, 1787.

25. Weichselbaum, T. E., and Somogyi, M., A method for the determination of small amounts of ketone bodies. J. Biol. Chem., 1941, 140, 5.

26. Crandall, L. A., Jr., A method for acetone bodies in blood applicable to the determination of small amounts of mercury. J. Biol. Chem., 1940, 133, 539.

27. Hubbard, R. S., Determination of the acetone bodies in blood. J. Biol. Chem., 1921, 49, 375.

28. Marriott, W. M., The blood in acidosis from the quantitative standpoint. J. Biol. Chem., 1914, 18, 507.

29. Somogyi, M., Effects of glucose feeding upon the ketonemia in healthy man. J. Biol. Chem., 1942, 145, 575.

30. Somogyi, M., and Weichselbaum, T. E., Ketonesparing effect of glucose. J. Biol. Chem., 1942, 145, 567.

31. Faber, K., and Hansen, K. M., The determination of the threshold of glycosuria and the errors involved. Acta med. Scandinav., 1923, 58, 372.

32. Albritton, E. C., The effect of frequent sampling on the form of blood sugar curves. Am. J. Physiol., 1924, 69, 548.

33. Bowman, K. M., and Kasanin, J., The sugar content of the blood in emotional states. Arch. Neur. \& Psychiat., 1929, 21, 342.

34. Lorenz, W. F., Sugar tolerance in dementia praecox and other mental disorders. Arch. Neurol. \& Psychiat., 1922, 8, 184.

35. Kooy, F. H., Hyperglycemia in mental disorders. Brain, 1919, 42, 214.

36. Alexander, F., and Portis, S. A., A psychosomatic study of hypoglycemic fatigue. Psychosom. Med., 1944, 6, 191.

37. Hinkle, L. E., Wolf, S., and Greenberg, D., Studies on diabetes mellitus; the effects of stressful life situations upon the circulating eosinophiles of diabetic persons, and their relation to the level of ketonemia. (To be published)

38. Hinkle, L. E., and Wolf, S., Experimental study of life situations, emotions, and the occurrence of acidosis in a juvenile diabetic. Am. J. M. Sc., 1949, 217, 130.

39. Root, H. F., The use of insulin and the abuse of glucose in the treatment of diabetic coma. J.A.M.A., 1945, 127, 557.

40. Kety, S. S., Polis, B. D., Nadler, C. S., and Schmidt, C. F., The blood flow and oxygen consumption of the human brain in diabetic acidosis and coma. J. Clin. Invest., 1948, 27, 500.

41. Quoted by John, H. J., Diabetic coma. J.A.M.A., 1929, 93, 425.

42. Warren, J. V., and Brannon, E. S., A method of obtaining blood samples directly from the hepatic vein in man. Proc. Soc. Exper. Biol. \& Med., 1944, 55, 144.

43. Mosenthal, H. O., and Lauber, F. U., Stability of the fasting blood sugar in diabetes mellitus. N. Y. State J. Med., 1944, 44, 1555.

44. Somogyi, M., Effects of insulin upon the production of ketone bodies. J. Biol. Chem., 1941, 141, 219.

45. Briggs, A. P., A study of a group of poorly regulated diabetic patients. Am. J. Digest. Dis., 1947, 14, 306.

46. Soskin, S., and Levine, R., Carbohydrate Metabolism. Univ. of Chicago Press, Chicago, 1946, p. 53.

47. Somogyi, M., and Kirstein, M. B., Changes in the blood ketone acids during artificial fever. Proc. Soc. Exper. Biol \& Med., 1940, 45, 640.

48. Courtice, F. C., and Douglas, C. G., The effects of prolonged muscular exercise on the metabolism. Proc. Roy. Soc., 1936, 119, 381.

49. Barach, J. H., Verbal discussion of ketosis of severe exercise. Proc. Am. Diab. Assoc., 1942, 2, 155.

50. Errebo-Knudsen, E. O., The ketone bodies in the blood of normal persons during muscular work. Rep. Steno, Mem. Hosp. (Copenhagen), 1946, 1, 12. (Abstracted in Diabetes Abstracts, 1948, 7, 22.)

51. Cannon, W. B., Bodily Changes in Pain, Hunger, Fear, and Rage. Appleton, New York, 2nd Ed., 1929.

52. Wolf, S., Pfeiffer, J. B., Ripley, H. S., Winter, O. S., and Wolff, H. G., Hypertension as a reaction pattern to stress: summary of experimental data on variations in blood pressure and renal blood flow. Ann. Int. Med., 1948, 29, 1056.

53. Hubbard, R. S., and Wright, F. R., Blood acetone bodies after the injection of small amounts of andrenalin chloride. J. Biol. Chem., 1921, 49, 385.

54. Bennett, L. L., Kreiss, R. E., Choh $\mathrm{Hao} \mathrm{Li}$, and Evans, H. M., Production of ketosis by the growth and adrenocorticotropic hormones. Am. J. Physiol., 1948, 152, 210.

55. Perera, G. A., Pines, K. L., Hamilton, H. B., and Vislocky, K., Clinical study of 11 dehydro-17- 
hydroxy corticosterone in hypertension, Addison's disease, and diabetes. J. Clin. Invest., 1949, 28, 803.

56. Bennett, L. L., Slessor, A., and Thorn, G. W., Effect of compound $\mathrm{E}$ on blood ketone bodies. J. Clin. Endocrinol., 1949, 9, 675.

57. Thorn, G. W., Forsham, P. H., Prunty, F. T. G., and Hills, A. G., A test for adrenal cortical insufficiency. J.A.M.A., 1948, 137, 1005.

58. Soskin, S., and Levine, R., Op. cit. (46). Pp. 119124.

59. Mirsky, I. A., Emotional hyperglycemia. Proc. Central Soc. Clin. Research, 1946, 19, 74.
60. Stevenson, I. P., and Duncan, C. H., Unpublished data.

61. Wolf, S., and Wolff, H. G., Human Gastric Function. Oxford University Press, New York, 1947.

62. Grace, W. J., Wolf, S., and Wolff, H. G., Life situations, emotions, and colonic function. Gastroenterology, in press.

63. Holmes, T. H., Goodell, H., Wolf, S., and Wolff, H. G., The Nose: An Experimental Study of Reactions Within the Nose in Human Subjects During Varying Life Experiences. C. C. Thomas, Springfield, in press. 